\title{
A ELASTICIDADE - RENDA DA DEMANDA DO SETOR PRIVADO DO ENSINO SUPERIOR PRESENCIAL NO BRASIL
}

\author{
Alexandre Oliveira (alexandre.oliveira@lasalle.org.br) \\ Cristiane Heleodoro Cardoso (crisheleodoro@gmail.com) \\ Daiane Rodrigues dos Santos (daianesantoseco@gmail.com) \\ Ludmila Santana de Azevedo Matos (1.santanadeazevedo@ hotmail.com) \\ Waldemar A. das Chagas Bezerra(adv.waldemar@gmail.com)
}

\section{Resumo}

O presente artigo analisou a elasticidade-renda da demanda com base nos dados do Censo do Ensino Superior e do Rendimento Médio da população Brasileira, com o intuito de demonstrar como a renda familiar influencia substancialmente no número de alunos matriculados do ensino superior Privado do País, nesse sentido, segundo Vasconcelos (2011), é de grande contribuição essa análise, pois, mediante aos resultados obtidos será possível a elaboração do planejamento empresarial do setor, ou seja, projetar as matrículas futuras, com base no crescimento da renda do País. O Ensino superior Brasileiro registrou um notório crescimento a partir dos anos 90, explicado pelas mudanças ocorridas na Lei de Diretrizes e Bases da Educação (LDB) de 1996, mudanças essas que possibilitaram a ampliação do setor privado, em mais de $500 \%$, desde a década 80 até o ano de 2018. Com o designo de garantir a sustentabilidade econômica dessa expansão, via setor privado, o Governo criou o Fundo de Financiamentos Estudantil (FIES) e o Programa Universidade para Todos (Prouni), programas esses que facilitaram a entrada das famílias de baixa renda no ensino Superior Privado.

Palavras-Chaves: Ensino Superior, Ensino Presencial, Renda, Universidade Privada.

\section{Introdução}

O Ensino como forma de melhoria na distribuição de renda e da qualidade de vida tem sido alvo de diversas pesquisas ao longo da história Brasileira, estudos como os desenvolvidos por Barros et. al (2002) e Langoni (2005) afirmam que, a desigualdade instalada no Brasil é um reflexo direto da lenta expansão do sistema educacional, portanto, um maior investimento em educação contribuirá para a diminuição gradual da desigualdade e consequentemente para crescimento econômico.

A desigualdade na distribuição de renda é real e por mais que a renda média tenha apresentado uma sensível melhora dentro do período analisado, os recursos financeiros, assim como os demais, são finitos e escassos, fazendo com que ingressar no ensino superior seja uma importante decisão e que envolve inúmeros trade-offs.

Mesmo diante deste paradigma, o estudo o publicado pelo o Fórum Nacional das instituições de Ensino Superior Católicas (2018), que considerou os dados obtidos de algumas das principais 
Instituições do Brasil, aponta uma projeção de crescimento da base de alunos até 2020 sendo impulsionados principalmente pelo Ensino à Distância (EAD), tanto pelo seu baixo custo, como por sua facilidade de adequação a rotina do estudante.

Portanto, o objetivo central deste artigo é estimar e analisar o impacto da elasticidade-renda da demanda do setor privado e presencial. A primeira parte consiste na contextualização do ensino superior. A segunda analisa o comportamento das matrículas e da renda média da população no período de 1984-2018. Já a terceira parte expõe os modelos utilizados e discorre sobre os resultados obtidos. Além desta Introdução e de um capítulo dedicado as conclusões finais.

\section{Contextualização do setor privado e presencial do ensino superior Brasileiro}

\subsection{Um breve histórico do ensino superior privado no Brasil}

Ao dissertar o ensino superior é necessário abordar seu histórico no Brasil, para obter-se uma visão holística de todo o processo desde a sua concepção passada aos dias atuais.

Saviani (2010), menciona o início precursor, mas, ainda, insipiente de que os jesuítas, no período colonial, deram os primeiros passos para a contribuição do ensino superior no Brasil, com os cursos de filosofia e teologia, porém não se pode confirmar.

De acordo com Sampaio (2000), os cursos superiores no Brasil, conforme registros, surgiram a partir de 1808, ano de chegada da família real em nossa terra, tendo em vista a necessidade em atender aos jovens da elite da época.

Mesmo com cursos de nível superior no Brasil, o direito de conhecimento era considerado elitistas, pois somente tinham acesso, os filhos da aristocracia colonial que tiveram por Napoleão, o direito de estudar na Europa cerceado. Esta parte da sociedade retinham o conhecimento, enquanto a maioria do povo era escravizada, ou subjugada por seus colonizadores.

Em 1920, surge a primeira Universidade no Brasil - A Universidade do Rio de Janeiro - criada pelo decreto de número 14.343 de sete de setembro de 1920 que reuniam a Escola Politécnica do Rio de Janeiro, a Faculdade de Medicina do Rio de Janeiro e a Faculdade de Direito do Rio de Janeiro, o qual foi um marco no Brasil.

De acordo com Sampaio (1991), a autonomia da Universidade era, enfim, discutida e deveria ser organizada da seguinte forma: 
"a) de maneira que se integrem num sistema único, mas sob direção autônoma, as faculdades profissionais (medicina, engenharia, direito), institutos técnicos especializados (farmácia, odontologia), e instituições de altos estudos (faculdades de filosofia e letras, de ciências matemáticas, físicas naturais, de ciências econômicas e sociais, de educação, etc.);

b) e de maneira que, sem perder o seu caráter de universalidade, se possa desenvolver, como uma instituição orgânica e viva, posta pelo seu espírito científico, pelo nível dos estudos, pela natureza e eficácia de sua ação, a serviço da formação e desenvolvimento da cultura nacional." (NAGLE, 1974),

Já o Ensino Superior Privado teve seu início no período republicano. Com a constituição da República em 1891, que possibilitou a abertura do ensino superior ao setor privado, porém caminhando a passos vagarosos até 1920.

Martins (2002) ressalta que no período Compreendido entre 1930 e 1945 houve uma intensa disputa entre a elite laica e a católica pelo controle da educação, principalmente do setor privado. Em 1931, durante a era Vargas, foi promovida uma reforma na educação que entre outras coisas, caminhava ao encontro da Constituição da República, mantendo o sistema de ensino superior aberto à iniciativa privada.

No período seguinte até 1968, a luta era com os professores e movimentos estudantis, que reivindicavam a absorção do setor privado pelas Instituição públicas, porém com a publicação da primeira LDB em 1961, caracterizou-se a vitória do setor privado (HERNÁNDEZ HUERTA, 2017).

Em 1964, com a ditadura, os movimentos estudantis forma reprimidos e as universidades públicas forma mantidas sobre forte vigilância. $\mathrm{O}$ controle feito pelo Estado faz deslocar a demanda ao setor privado que passou a atender cerca de $75 \%$ dos 1.400 .000 alunos matriculados em 1980.

Após o Regime militar (1985 até 1995) o número de matrículas esteve relativamente estável e foi registrado um decréscimo da participação das instituições privadas no setor. De 1995 em diante é notório o crescimento das instituições privadas caracterizado fundamentalmente pela nova LDB de 1996.

O ensino superior no Brasil constituiu um acontecimento tardio: 
[...] as primeiras universidades na América Latina foram criadas nos séculos XVI e XVII, quando já existiam várias universidades na Europa. Ao contrário da colonização espanhola, na América Latina os portugueses mostravam-se hostis à criação de escolas superiores e de universidades em sua colônia brasileira. As primeiras instituições de ensino superior (IES) no Brasil foram criadas somente no início do século XIX, com a transferência da corte portuguesa, em 1808, para a colônia. Elas tinham por objetivo apenas fornecer quadros profissionais para desempenhar diferentes funções ocupacionais na corte. (NEVES E MARTINS, 2014).

\subsection{Programas de acesso ao ensino superior privado}

Em 1999 foi criado o Fundo de financiamento do Ensino superior (FIES). Um programa destinado a financiar total ou parcialmente alunos regularmente matriculados em cursos superiores e não gratuitos. Apesar de ter iniciado em 1999, ele foi estruturado somente em 2001, através da Lei 10.260. Desde sua criação o programa passou por diversas modificações normativas.

Em 2004 foi criado o Prouni - Programa Universidade para Todos, com o objetivo conceder bolsas de estudo integrais e parciais em cursos de graduação e sequenciais de formação específica, em instituições privadas de ensino superior registrou no primeiro ano 112.275 bolsas, sendo 71.950 integrais e 40.370 parciais, fechando o ano de 2018 com aproximadamente 417.276 bolsas concedidas, dessas 182.474 integrais e 234.629 parciais. O programa, desde sua criação até o ano de 2018, já atendeu cerca de 2,47 milhões de estudantes, com 69\% de bolsas integrais.

Após a criação do Prouni o governo se esforçou no sentido de criar uma aproximação entre os dois programas. Com a Portaria Normativa $\mathrm{n}^{\circ}$ 30, de 2007 o bolsista parcial do Prouni poderia financiar até 50\% do montante não coberto, a Figura 1 mostra a evolução dos dois programas e o resultado dessa aproximação. Então, em 2010, o percentual passível de financiamento alcançaria a totalidade, essa modificação normativa tornou os programas complementares, favorecendo a permanência do estudante no ensino superior e em 2015 sofreu medidas de ajustes para frear o crescente ritmo de expansão do programa. 
Figura 1 - Matrículas na rede privada, por tipo de Financiamento/bolsa (2009-2017)

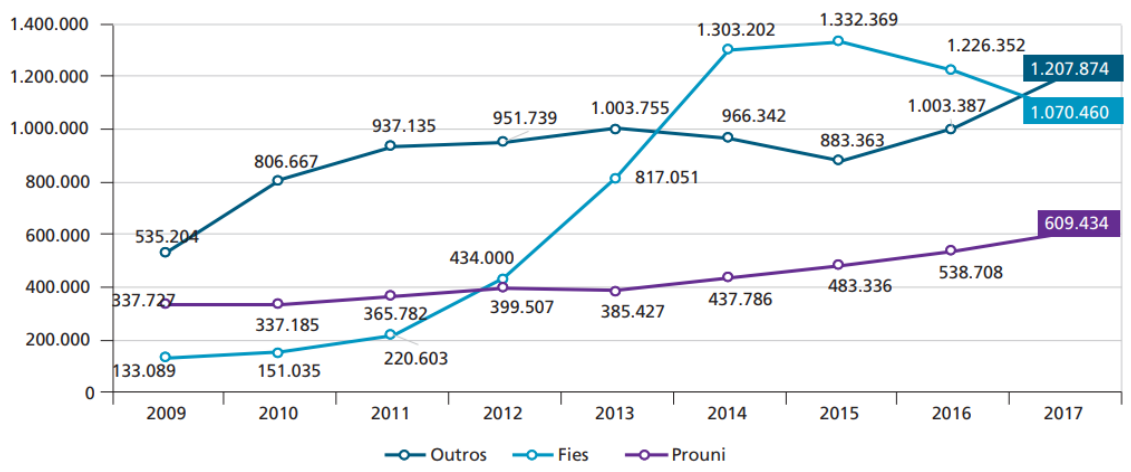

Fonte:Inep/MEC.

Segundo o Ministério da Educação - MEC, o "Novo Fies instituído pela Lei 13.530/2017, adotou novos parâmetros para o ingresso de estudantes possibilitando juros zero a quem mais precisa e uma escala de financiamentos que varia conforme a renda familiar do candidato. $\mathrm{O}$ novo FIES traz melhorias na gestão do fundo, dando sustentabilidade financeira ao programa a fim de garantir a sustentabilidade do programa e viabilizar um acesso mais amplo ao ensino superior". Com isso, haverá o limite superior correspondente a 2 salários mínimos e meio de renda familiar per capita, passou a priorizada também a oferta em cursos das regiões Norte, Nordeste e Centro-Oeste, visando corrigir desigualdades regionais existentes no país. Para comparação, atualmente $60 \%$ dos contratos de financiamento se encontram nas regiões Sul e Sudeste e no Distrito Federal, entre outras alterações.

Baseado na reportagem divulgada pela Associação Brasileira de Mantenedoras de Ensino Superior (ABMES), a Figura 2 mostra que o Fies fechou o ano de 2018 com menos de 85 mil contratos, sendo o pior desempenho desde o ano de 2010.

Figura 2 - Evolução dos contratos do FIES (2009-2018)

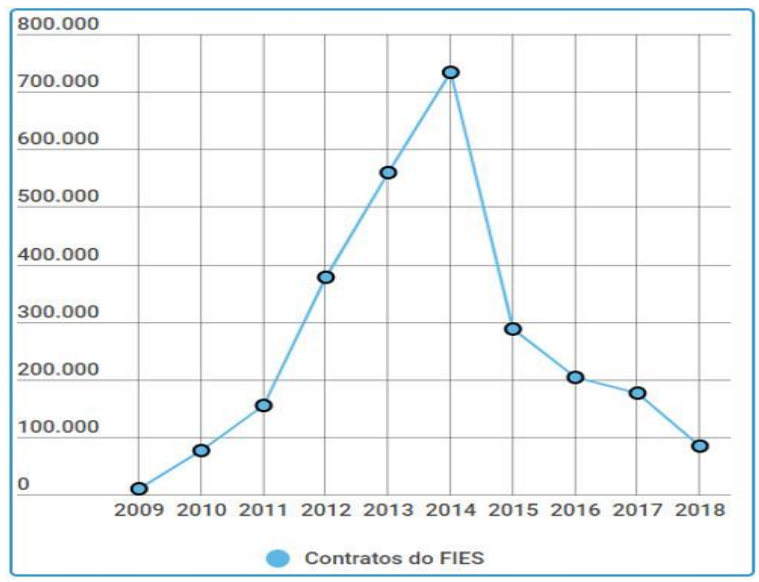

Fonte: ABMES 
Contudo, a criação do FIES pode ser justificada pela própria história do país. De acordo com Jardim (2018):

"No Brasil, o acesso à Universidade de estudantes oriundos das camadas populares, afrodescendentes, entre outros que historicamente estiveram à margem do Ensino Superior, é fato relativamente recente. A implementação de políticas de inclusão social - via ações afirmativas - vem se materializando preponderantemente no campo da educação superior e no mercado de trabalho. Trata-se de matéria polêmica, que desperta o interesse da sociedade em geral e, no senso comum, o debate polariza-se entre os que pregam que as denominadas políticas de ação afirmativa - ao contrário de trazerem benefícios - estigmatizam ainda mais tais segmentos sociais alijados" (JARDIM, 2018).

\section{Comportamento das matrículas e da renda média da população}

\subsection{Evolução das matrículas do ensino superior}

O ensino superior privado passou por profundas mudanças no Brasil. Para Tachibana et al. (2015), a expansão do ensino superior no Brasil nas últimas duas décadas foi conduzida, majoritariamente, pelo setor privado. De acordo com os autores: Durham (1998) e Souza (2003) a participação do setor público nas matrículas da graduação presencial era maior que a do setor privado até o final da década de 1960. A partir de 1970, contudo, a situação começa a se inverter, e, na década seguinte, o setor privado assume papel majoritário no número de matrículas. Essa participação, de 64,3\% em 1980, se eleva para 67,1\% em 2000, e alcança um nível ainda mais elevado nos anos posteriores, atingindo 71,1\% em 2013. (Tachibana et al. p. 7, 2015). como exposto na Figura 3, a partir da tabulação e análise dos dados é possível afirmar que o sistema caminha para uma inversão de elitizado para um sistema de massificação, sobretudo durante o período em que o partido dos trabalhados esteve governando o Brasil.

Figura 3 - Matrículas no ensino superior presencial - Brasil (1984-2018)

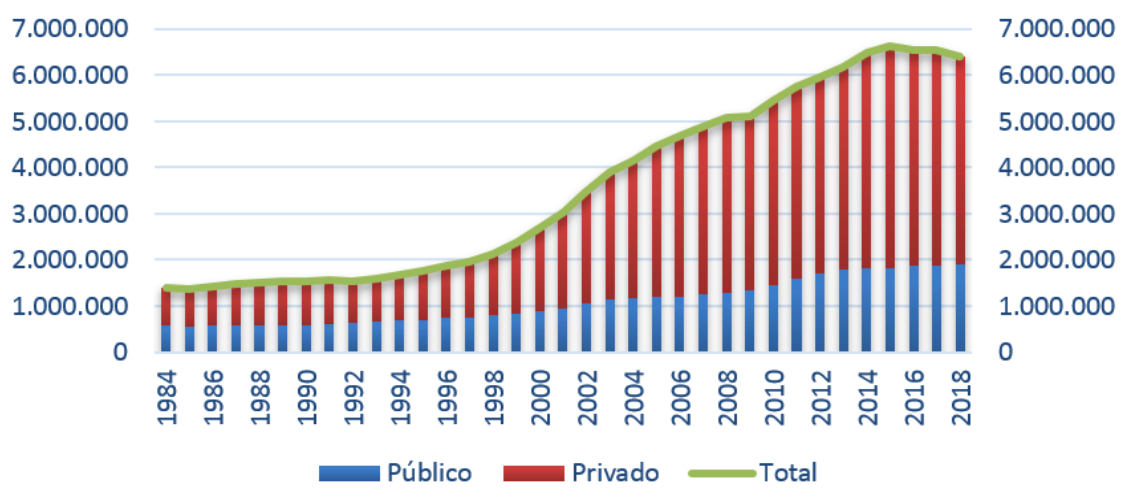

Fonte:Inep/MEC. 
Na TABELA 1 é possível verificar que essa massificação se deu principalmente através do setor privado, que somente no período analisado teve um crescimento médio superior a $500 \%$, enquanto o público apresentou aproximadamente 333\%. Aumentar o número de vagas, facilitar o acesso e melhorar a educação são necessidades para uma mão de obra melhor qualificada e ainda ajuda a criar saltos tecnológicos que beneficiam toda a cadeia de produção de um país.

TABELA 1- Evolução das Matrículas na Educação superior Presencial - Brasil (1984-2018)

\begin{tabular}{|c|c|c|c|c|c|}
\hline \multicolumn{6}{|c|}{ Evolução das Matrículas na Educação superior Presencial - Brasil (1984-2018) } \\
\hline Ano & Público & Privado & Total & \% público & \%privado \\
\hline 1984 & 571.879 & 827.660 & 1.399 .539 & 40,86 & 59,14 \\
\hline 1994 & 690.450 & 970.584 & 1.661 .034 & 41,57 & 58,43 \\
\hline 2004 & 1.178 .328 & 2.985 .405 & 4.163 .733 & 28,30 & 71,70 \\
\hline 2014 & 1.821 .629 & 4.675 .696 & 6.497 .325 & 28,04 & 71,96 \\
\hline 2018 & 1.904 .554 & 4.489 .690 & 6.394 .244 & 29,79 & 70,21 \\
\hline $\begin{array}{c}\% \text { de Crescimento } \\
\text { Médio }\end{array}$ & 333,03 & 542,46 & 456,88 & $* * *$ & $* * *$ \\
\hline
\end{tabular}

Fonte: Elaboração Própria.

\subsection{Evolução da renda média da população Brasileira}

Para o presente trabalho foi utilizado o Rendimento médio real de todas as fontes que é medido pelo instituto Brasileiro de geografia e estatísticas (IBGE), através da Pesquisa Nacional por amostra de domícilios Contínua Mensal (PNAD) e reúne as informações de rendimentos provenientes do trabalho, assim como os provenientes de outras fontes, como por exemplo: aluguéis, pensões, aposentadorias e outros rendimentos. Pois entende-se que a mensalidade do ensino superior pode advir de quaisquer fontes de renda disponíveis ao alunado.

A Figura 4, abaixo exposta, foi produzida com base na harmonização das informações do arcevo histórco do IBGE e foi deflácionado pelo Indíce Nacional de Preços ao Consumidor (INPC) de setembro de 2018. Tal indíce é usado para ajustar a valor presente o poder de compra do salário da população assalariada e com rendimentos mais baixos (1 até 5 salários Mínimos). 


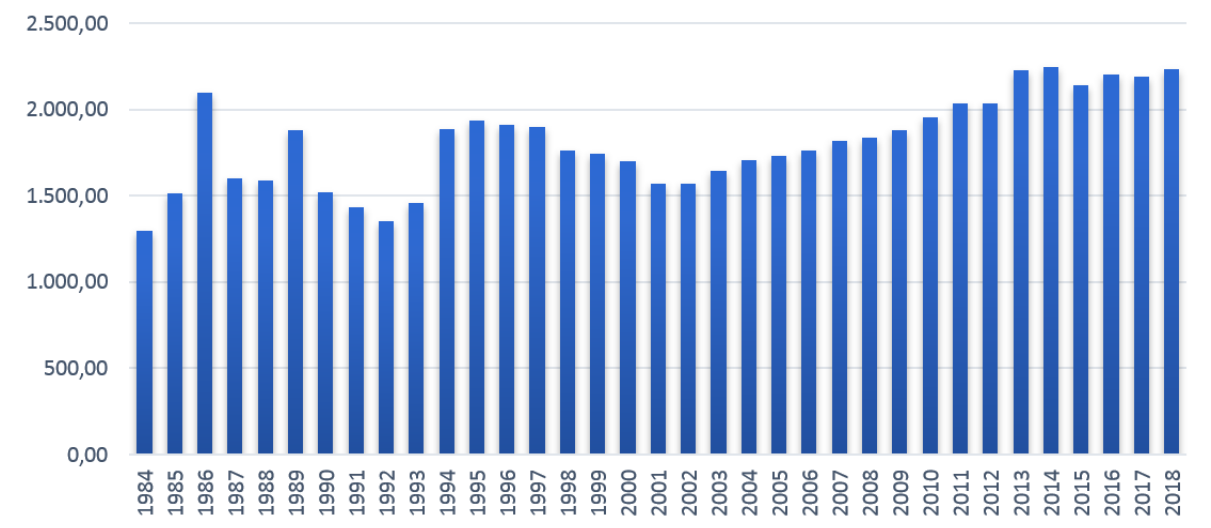

Fonte:IBGE/ Elaboração própria.

Em relação aos rendimentos de todas as fontes, de acordo com os resultados, é possível notar que refletem a realidade das mudanças econômicas, sociais e políticas vividas pelo Brasil em cada período. De 2004 a 2014 o Brasil caminhou para redução da desigualdade social e o aumento do rendimento médio, porém em 2015 houve um retrocesso quando este rendimento chegou a ser de $\mathrm{R} \$ 2.137,13$ com uma redução de aproximadamente $5 \%$ se comparado ao Período anterior (2014). Entre 1984 e 2018 o indicador apresentou um crescimento de 42\%.

\section{Modelos utilizados e resultados obtidos}

\subsection{Regressão linear}

A regressão linear simples consiste no fato de estabelecer uma função matemática linear que relacione duas variáveis e sua análise permite mensurar em valores o quanto uma variável influência no comportamento da outra. Da mesma forma como a média é usada para resumir uma variável aleatória, a reta de regressão é usada para resumir a estimativa linear entre duas variáveis aleatórias, cuja relação se pressupõe causa e efeito, de explanação do comportamento entre as variáveis LAPPONI (1997).

Nos casos em que a variável dependente e a variável independente são transformadas em log variáveis, a interpretação é uma combinação dos casos linear-log e log-linear (Benoit $\boldsymbol{e t}$ al. 2011). Em outras palavras, a interpretação é dada como uma mudança percentual esperada em $\mathrm{Y}$ quando $\mathrm{X}$ aumenta em alguns percentagem. Tais relacionamentos, onde $\mathrm{Y}$ e X são transformados em log, são comumente referidos como elasticidade na econometria.

A regressão estuda a correlação das variáveis, que é uma medida de do grau de relação existente entre as variáveis analisadas, para saber se existe ou não correlação entre X e Y é necessário efetuar o cálculo do valor de R e interpretar seu resultado. Segundo a classificação sugerida por 
Santos (2007), exposta no QUADRO 1, o nível de correlação das variáveis pode ser definido como:

QUADRO 1 - Classificação da correlação.

\begin{tabular}{|c|c|}
\hline $\begin{array}{c}\text { Coeficiente de } \\
\text { correlação }\end{array}$ & Correlação \\
\hline$R_{x y}=1$ & Perfeita positiva \\
\hline $0,8 \leq R_{x y}<1$ & Forte positiva \\
\hline $0,5 \leq R_{x y}<0,8$ & Moderada positiva \\
\hline $0,1 \leq R_{x y}<0,5$ & Fraca positiva \\
\hline $0 \leq R_{x y}<0,1$ & Ínfima positiva \\
\hline 0 & Nula \\
\hline$-0,1 \leq R_{x y}<0$ & Ínfima negativa \\
\hline$-0,5 \leq R_{x y}<-0,1$ & Fraca negativa \\
\hline$-0,8 \leq R_{x y}<-0,5$ & Moderada negativa \\
\hline$-1 \leq R_{x y}<-0,8$ & Forte negativa \\
\hline$R_{x y}=-1$ & Perfeita negativa \\
\hline
\end{tabular}

Fonte: Santos (2007).

\section{2. Elasticidade-renda da demanda}

Um dos fatores que influencia o consumo é a renda. Segundo Vasconcellos (2011), a elasticidade-renda da demanda mensura a variação percentual da demanda dada uma variação na renda do consumidor, ou seja, o cálculo da elasticidade-renda da demanda indica o quanto a mais o consumidor está disposto a consumir, ou deixar de consumir se sua renda variar, positiva ou negativamente. Ela é calculada através da FÓRMULA 1:

$$
\begin{gathered}
\text { Elasticidade }- \text { Renda } \\
\text { da Demanda }
\end{gathered}=\frac{\begin{array}{c}
\text { Variação Percentual } \\
\text { da quantidade Demandada }
\end{array}}{\begin{array}{c}
\text { Variação Percentual } \\
\text { da Renda }
\end{array}}=\frac{\triangle \% \text { QD }}{\triangle \% \mathrm{R}}
$$

E de acordo com Lacombe (2004) o resultado obtivo pode ser classificada entre:

- Bens necessários: $0<\varepsilon_{\mathrm{R}}<1$

- Bens de luxo: $\varepsilon_{R}>1$

Ou seja, um bem será considerado de luxo sempre que o aumento da quantidade demandada for superior ao aumento da renda. Portanto, quando a renda aumentar, seu consumo aumentará de 
forma superior e quando a renda for reduzida, a demanda por esse bem tenderá a cair drasticamente, já que é o primeiro item a ser cortado da cesta de consumo caso haja uma retração da renda do consumidor. Os bens necessários são aqueles que quando a renda aumenta, o seu consumo aumenta de forma não mais que proporcional.

Como o presente estudo utilizou-se da regressão linear como modelo econométrico para mensurar os resultados, neste caso, para Gujarati (2008) o modelo log-linear é o indicado para medir a elasticidade e seus resultados são obtidos através da FÓRMULA 2.

$$
\log Y i=\alpha+\beta X i+\varepsilon i
$$

Ainda conforme Gujarati (2008), um aspecto atraente do modelo log-linear, que o tornou muito difundido nos trabalhos aplicados, é que o coeficiente angular beta 2 mede a elasticidade de do bem y em relação a variável x (preço do bem (y), preço do bem relacionado (z) ou renda, por exemplo), isto é, a variação percentual de Y correspondente a uma dada variação percentual (pequena) do bem $X$.

\subsection{Resultados Obtidos}

Este estudo utilizou como base de mensuração de resultados o cálculo da regressão linear demanda do ensino superior privado e presencial no brasil, o recorte temporal analisado compreende os anos de 1984 até 2018.

A regressão linear pretende estimar a variação das matrículas (variável dependente), a partir da variação da média dos rendimentos da população (variável independente). Para obter tal resultado, o cálculo foi efetuado utilizando a ferramenta de análise de dados do excell e apresentou o seguinte resultado.

TABELA 2- Resultados da regressão linear

\begin{tabular}{lc}
\hline \multicolumn{2}{c}{ Estatística de regressão } \\
\hline R múltiplo & 0,7 \\
R-Quadrado & 0,6 \\
R-quadrado ajustado & 0,5
\end{tabular}

Fonte: Elaboração própria.

$\mathrm{O} \mathrm{R}^{2}$ é o coeficiente de determinação ou coeficiente de explicação e mede o percentual de variação de Y que é explicado pela variável X, ou seja, a análise desse resultado sugere que 
$60 \%$ da variação das matrículas é explicado pela variação da renda média, sendo os outros $40 \%$ explicados por outros fatores tais como os desejos e necessidades do indivíduo, assim como sua perspectiva de vida entre outros.

Já o cálculo da elasticidade-renda da demanda é medido pela regressão linear como exposto na Fórmula 2, sendo uma função que relaciona a variável independente, a renda (x) com a variável dependente, o $\mathrm{n}^{\circ}$ de Matrículas (y). Ou seja, ele mede o acréscimo que o número de matrículas sofrerá caso haja um acréscimo na renda do estudante, ou do patrocinador do mesmo. O cálculo apontou uma elasticidade de aproximadamente 2,96, ou seja, para cada unidade acrescida na renda, a demanda pelo ensino superior será acrescida de aproximadamente 2,96 unidades.

Vale ressaltar que, os coeficientes de relação do modelo demonstraram resultados positivos e que o modelo está bem ajustado, apresentando resultados de Teste F e P-valor menores que o nível se significância, neste caso 5\%, indicando que de fato há uma correlação linear entre X e Y, ou seja, quanto maior a renda maior será o número de matrículas.

O que significa dizer que, a entrada no ensino superior presencial pode ser considerada como um bem elástico, classificado como um bem superior (de luxo) e que sua variação depende principalmente da renda do indivíduo, mas também é influenciada por outros fatores, como por exemplo, a entrada no ensino superior a distância que apresenta um custo menor ou a escolha de ingressar em um curso técnico ou profissional, ou ainda, o grau de ambição ou a perspectiva de futuro do indivíduo.

\section{Considerações finais}

O ensino superior Brasileiro é formado em sua maioria por instituições privadas que, em sua maioria visam ao lucro, até mesmo em detrimento da qualidade do ensino, enquanto o foco principal deveria ser na formação e promoção técnico-cientifica, economia e cultural dos discentes (NUNES, 2012).

Portanto, com base nos resultados obtidos é possível concluir que a renda é o principal fator que impacta o acesso de Estudantes de baixa renda ao Ensino superior. Mesmo com os programas de financiamentos estudantis existentes no País, é importante que o Governo Brasileiro se atente a cada vez mais ampliar e aprimorar essas formas de acesso do alunado, pois somente através da educação e qualificação da população será possível melhorar a distribuição da renda e reduzir a desigualdade social. 


\section{REFERÊNCIAS}

A Lei de Diretrizes e Bases da Educação Brasileira (LDB 9394/96). Disponível em: <http://www.planalto.gov.br/ccivil_03/leis/19394.htm >Acesso em: 20 de outubro de 2019.

Agência IBGE Notícias. Rendimento Médio de todos os trabalhos (2016-2017).Disponível em: $<$ https://agenciadenoticias.ibge.gov.br/agencia-sala-de-imprensa/2013-agencia-de-noticias/releases/20843-pnadcontinua-10-da-populacao-concentravam-quase-metade-da-massa-de-rendimentos-do-pais-em-2017 >Acesso em: 07 de novembro de 2019.

Agência IBGE Notícias. Rendimento Médio de todos os trabalhos (2018). Disponível em: < https://agenciadenoticias.ibge.gov.br/agencia-sala-de-imprensa/2013-agencia-de-noticias/releases/25700-pnadcontinua-2018-10-da-populacao-concentram-43-1-da-massa-de-rendimentos-do-pais >Acesso em: 07 de novembro de 2019.

Associação Brasileira de Mantenedoras de Ensino Superior (ABMES). Fies Termina Ano Com O Menor Número De Novos Contratos Desde 2010. Disponível em:

$<$ http://www.abmes.org.br/noticias/detalhe/3110/fies-termina-ano-com-o-menor-numero-de-novos-contratosdesde-2010> Acesso em: 30 de setembro de 2019.

BARROS, Ricardo Paes de; FRANCO, Samuel; MENDONÇA, Rosane. A recente queda da desigualdade e o acelerado progresso educacional brasileiro da última década. Rio de Janeiro, IPEA, Texto para Discussão, $\mathrm{n}^{\circ}$ 1304, setembro/2007 Disponível em:< http://repositorio.ipea.gov.br/bitstream/11058/1439/1/TD_1304.pdf> Acesso em: 29 de setembro de 2019.

BENOIT, Kenneth. Linear Regression Models with Logarithmic Transformations. Methodology Institute,London School of Economics. March,2011. Disponível em: <https://kenbenoit.net/assets/courses/ME104/logmodels2.pdf> Acesso em: 30 de setembro de 2019.

Cálculo deflácionario pelo Indíce Nacional de Preços ao Consumidor (INPC). Disponível em: < https://calculoexato.com.br/parprima.aspx?codMenu=FinanAtualizaIndice>. Acesso em: 07 de novembro de 2019.

DURHAM, E. R. Uma política para o ensino superior brasileiro: diagnóstico e proposta. São Paulo: Universidade de São Paulo; Nupes, 1998. 66p. (Documento de Trabalho Nupes n. 1/98).

Fundo de Financiamento Estudantil (FIES). Disponível em: < http://fies.mec.gov.br/> Acesso em: 07 de outubro de 2019.

GUJARATI, D. N.; PORTER, D. C. Econometria básica. 5. ed. Porto Alegre: AMGH, 2011. 924 p.

HERNÁNDEZ HUERTA, José Luis. La rivolta studentesca brasiliana del '68. Considerazioni a partire dalla stampa quotidiana. In: TODARO, Letterio. Pedagogia, istanze di emancipazione trasformazioni dell'immaginario educativo tra gli anni '60 e '70 del Novecento. Roma, 2017.

IBGE Brasil em síntese: rendimento de todos os trabalhos (2007-2015). disponível em:<https://brasilemsintese.ibge.gov.br/trabalho/rendimento-de-todos-os-trabalhos.html> Acesso em: $07 \mathrm{de}$ novembro de 2019.

IBGE | Séries Estatísticas \& Séries Históricas : Rendimento médio mensal de todos os trabalhos (1981-2007). Disponível em:

$<$ https://seriesestatisticas.ibge.gov.br/series.aspx ?no=7\&op=0\&vcodigo=FDT800\&t=rendimento-medio-mensaltodos-trabalhos-pessoas> Acesso em: 07 de novembro de 2019.

JARDIM, Tânia. Destinos (im)prováveis: a formação em serviço social transformando trajetórias. 1 ed.-Rio de Janeiro, 2018.

LANGONI, C. Distribuição de renda e desenvolvimento econômico no Brasil. $3^{\mathrm{a}}$ ed. Rio de Janeiro: FGV, 2005.

LAPPONI, J. C. Estatística usando Excel 5 e 7. São Paulo: Lapponi, 1997

MARTINS, 2002 Antonio Carlos Pereira Martins. Ensino superior no Brasil: da descoberta aos dias atuais em Acta Cirúrgica Brasileira, 17 (3) (2002), pp. 04-06, São Paulo

NAGLE, A., 1974 - Educação e Sociedade na Primeira República. S.P. EPU - Editora Pedagógica Universitária Ltda. e Editora da Universidade de São Paulo. 
NEVES, Clarissa; MARTINS, Carlos; 2014. Disponível em:

<http://repositorio.ipea.gov.br/bitstream/11058/9061/1/Ensino\%20superior\%20no\%20Brasil.pdf > Acesso em: 25 de outubro 2019.

NORONHA, João. Fórum Nacional das IES Católicas. Setor de Educação no Brasil. Disponível em: < http://anec.org.br/wp-content/uploads/2018/08/Financiamento-Santander-1.pdf> Acesso em: 25 outubro 2019.

NUNES, Edson de Oliveira. Educação Superior no Brasil: estudos, debates, controvérsias, Rio de Janeiro: Garamond, 2012. História UFRJ. Disponível em: < https://ufrj.br/historia>. Acesso em: 25 outubro 2019.

Programa Universidade para todos - Prouni. Disponível em: < http://prouniportal.mec.gov.br/o-programa> Acesso em: 07 de outubro de 2019.

SAMPAIO, HELENA. Documento de Trabalho 8/91: Evolução do ensino superior Brasileiro 1808-1990. Núcleo de Pesquisas sobre o ensino Superior da Universidade de São Paulo.1991

SAMPAIO, HELENA. Ensino superior no Brasil: O setor privado. São Paulo. FAPESP, 2000.

SAMPAIO, HELENA. O setor privado de ensino superior no Brasil: continuidades e transformações. Ensino Superior: Campinas: Unicamp, 2011.

SANTOS, C. M. A.; Estatística Descritiva - Manual de auto-aprendizagem; Edições Sílabo; 2007.

SAVIANI, Dermeval. A expansão do ensino superior no Brasil: Mudanças e continuidades. Poíesis pedagógica, v. 8, n.2, p. 4-17, 2010.

Sinopses Estatísticas da Educação Superior - Graduação. Disponível em:

<http://portal.inep.gov.br/web/guest/sinopses-estatisticas-da-educacao-superior>. Acesso em: 07 outubros de 2019.

SOUSA, J. V. O ensino superior privado no Distrito Federal: uma análise de sua recente expansão (19952001). 2003. 279f. Tese (Doutorado) - Universidade de Brasília, Brasília, 2003.

TACHIBANA, Thiago Yudi et al. Policy Paper, n. 14, dez .2015. Disponível em: <https://www.insper.edu.br/wp-content/uploads/2018/09/Ensino-superior-no-Brasil.pdf>. Acesso em: 28 outubro 2019.

VASCONCELlOS, Marco Antonio Sandoval de. Economia: Micro e Macro: Teoria e exercícios, glossário com 300 principais conceitos econômicos. -5. Ed.- São Paulo: Atlas, 2011. 